\title{
Leaf area and pubescence drive sedimentation on leaf surfaces during flooding
}

\author{
Lena Kretz $^{1}\left(\mathbb{D} \cdot\right.$ Carolin Seele $^{1} \cdot$ Fons van der Plas $^{1,2} \cdot$ Alexandra Weigelt $^{1,2} \cdot$ Christian Wirth $^{1,2,3}$
}

Received: 10 September 2019 / Accepted: 4 May 2020 / Published online: 17 May 2020

(c) The Author(s) 2020

\begin{abstract}
Worldwide, stream water is increasingly loaded with sediments and nutrients, due to processes such as accelerated soil erosion and overfertilization caused by agricultural intensification. This leads to increases in eutrophication and silting up of bottom sediments. Floodplains can play an important role in mitigating these problems, by removing sediment from rivers via water filtration and retention. Fine sediment is accumulated on the soil in between plants as well as on plant surfaces. However, it is still poorly understood how plant species facilitate leaf surface sedimentation via their leaf traits. In a flume experiment, we investigated to what extent the leaf traits (area, length, perimeter, pinnation, pubescence, surface roughness, flexibility and wettability) influence leaf surface sedimentation. We exposed leaves of 30 plant species to an artificial flood, and measured the fine sediment load the leaves captured after $24 \mathrm{~h}$. Our results show that leaf traits overall explain $65 \%$ of the variation of fine sedimentation on leaves. Especially adaxial pubescence and leaf area strongly drove sedimentation. Hairy leaves accumulate more sediment per leaf area, presumably, because hairs create a buffer zone of reduced flow velocity which enhances sedimentation between the hairs. Additionally, for leaves with no or few hairs, sedimentation decreased with increasing leaf area, because most likely the more turbulent boundary layer of larger leaves allows less sediment to settle. Our results provide a first understanding of how plants can be selected based on their leaf traits for maximizing the sediment retention on floodplains, thereby providing a key ecosystem service.
\end{abstract}

Keywords Functional traits $\cdot$ Flume experiment $\cdot$ Floodplain $\cdot$ Sediment retention

Communicated by Russell Monson.

Electronic supplementary material The online version of this article (https://doi.org/10.1007/s00442-020-04664-2) contains supplementary material, which is available to authorized users.

The leaf surfaces of herbaceous plants capture sediments during floods. We showed thatspecific leaf traits explain over $65 \%$ of the variation in sedimentation on leaves. Leaf pubescence density and type, leaf area, and interactions between pubescence and area were most important as traits controlling sedimentation rates.

Lena Kretz

lena.kretz@uni-leipzig.de

1 Systematic Botany and Functional Biodiversity, Life science, Leipzig University, Leipzig, Germany

2 German Centre for Integrative Biodiversity Research (iDiv) Halle-Jena-Leipzig, Leipzig, Germany

3 Max Planck Institute for Biogeochemistry, Jena, Germany

\section{Introduction}

Worldwide, sediment and nutrient loads in stream water are increasing due to anthropogenic activities (Sharma and Rai 2004; Quilbé et al. 2006; Hunter and Walton 2008; Jones et al. 2012). Industrial agriculture and forestry, but also sealing of soil (e.g. covering of soil with buildings or roads) and mining cause overfertilization of soils, soil erosion and surface water runoff that are jointly responsible for increases in the sediment and nutrient load of streams (Turnpenny and Williams 1980; Carpenter et al. 1998; Hancock 2002; Grizzetti et al. 2008; Bernhardt and Palmer 2011; Berendse et al. 2015). Consequences are eutrophication of the stream water and silting up of sediment in branches and the mouth of the stream (Bouwman et al. 2013; Habersack et al. 2016). Under natural conditions, floods counteract these processes by depositing sediment particles and nutrients from streams into floodplains, which function as a sink for both (Naiman and Décamps 1997; Asselman et al. 2003; Walling et al. 2003; Taylor et al. 2008; Bouwman et al. 2013). Thereby, 
floodplains provide key ecosystem services of sediment and nutrient retention and water filtration (Hopkins et al. 2018; Conte et al. 2011). However, river straightening and embankment have dramatically reduced floodplain area, so that floodplains count worldwide as one of the most threatened ecosystems (Naiman and Décamps 1997; Tockner and Stanford 2002; Thoms 2003; Steiger et al. 2005). To restore the ecosystem service of water filtration, many countries have launched programs to reactivate former floodplains. In addition, existing floodplain areas could be managed to maximise retention capacities during overbank flow conditions. To achieve this, we need to improve our understanding of how plant and vegetation characteristics enhance sedimentation.

It is still unknown if and how functional and structural diversity of floodplain vegetation enhances retention and water filtration. Sediment retention is a complex phenomenon that depends on different biogeomorphic processes in the floodplain (Corenblit et al. 2011). While coarse sedimentation is mostly influenced by the geomorphology of the floodplain, the vegetation type and structure are most relevant for fine sedimentation (Corenblit et al. 2011; Manners et al. 2013). Communities of herbaceous pioneer vegetation are more efficient in accumulating fine sediments compared to shrublands and floodplain forests (Corenblit et al. 2009). Furthermore, the ability of plant communities to accumulate sediments might increase with increasing diversity and associated functional and structural complexity of the plant communities (Emerson and Kolm 2005). Various studies have shown that vegetation acts as a sediment filter causing sedimentation between the plants and on the plant surfaces; however, none of these studies focused on species identity and diversity effects (Karr and Schlosser 1978; Blanco-Canqui et al. 2004; Pan et al. 2011; Gurnell et al. 2012; Kervroëdan et al. 2018). Elliott (2000) emphasized the importance of sedimentation on plant surfaces in addition to the vertical structural complexity of the plant. Instream stands of macrophytes slow down flow velocity and reduce turbulence within the stand, which causes accumulation of fine sediment (Sand-Jensen 1998; Clarke 2002; James et al. 2002; Palmer et al. 2004; Ortiz et al. 2013). On-plant sedimentation is low for macrophytes, since they have adapted leaves that streamline with the water flow (Jones et al. 2012; Sand-Jensen 1998; Rovira et al. 2016). Herbaceous floodplain species, however, are not well adapted to inundation, so the on-plant sedimentation may play an important role for sediment retention (Elliott 2000).

To our knowledge, there is currently no study that investigated the on-plant sedimentation of herbaceous floodplain vegetation after inundation and related it to plant leaf traits. Plant leaves vary in size, morphology and surface structure (Koch et al. 2009), and it is possible that these and other leaf traits determine sediment accumulation. Studies focusing on the instream vegetation have shown that for macrophytes flat, smooth and flexible leaves capture the least sediment in the surrounding (Sand-Jensen 1998; Jones et al. 2012; Rovira et al. 2016). Furthermore, a study using artificial leaves showed that shape, serration, roughness and flexibility of leaves have an impact on the drag force and turbulence intensity, which are expected to alter sedimentation (Albayrak et al. 2012). Also, studies on airborne particle deposition on leaf surfaces found trait effects on deposition rate. Since fluid dynamics are similar for water and air (except that water is more strongly affected by the viscosity of the fluid), studies on airborne deposition may also be informative for sedimentation on leaves under water. The deposition of airborne particles is strongly affected by leaf area, surface waxes (wettability), pubescence and surface roughness (Wedding et al. 1975; Little 1977; Burkhardt et al. 1995; Sæbø et al. 2012; Weber et al. 2014).

There are five main classes of leaf traits that likely determine the sedimentation on leaf surfaces. First, hair density on the leaf surface has a positive effect on airborne particle adhesion (Räsänen et al. 2013; Weber et al. 2014). Hairs act as obstacles to the flow, building a buffer zone of reduced flow velocity (Wedding et al. 1975). However, very dense hairs on the leaf surface can also cause a cleaning effect by enhancing water runoff (Otten and Herminghaus 2004) leading to reduced sedimentation. Second, the total leaf area may influence sedimentation, although negative effects as well as non-significant effects have been reported for studies on airborne particles (Sæbø et al. 2012; Räsänen et al. 2013; Weber et al. 2014). Flow dynamics of the boundary layer on the leaf surface cause greater turbulence with distance and, consequently, less sedimentation on the leaf surface. Third, flexible leaves streamline better with the flow, while stiff leaves cause greater near-surface turbulence (Horn and Richards 2007; Chen et al. 2011; Nepf 2012). Forth, the roughness of a leaf can increase sedimentation, which was shown for macrophytes (Jones et al. 2012) and for airborne particle deposition on terrestrial plant leaves (Sand-Jensen 1998; Weber et al. 2014). Fifth, wettability of leaves depends on various traits and mechanisms, including repellence due to wax layers (the lotus effect), pubescence (Otten and Herminghaus 2004; Koch et al. 2008; Bhushan et al. 2009) and the ultra-structure roughness (Bhushan et al. 2009; Wang et al. 2014). So far, increasing and decreasing effects of wettability on sedimentation were found (Neinhuis and Barthlott 1998; Räsänen et al. 2013). However, it is still unclear how all these mentioned leaf traits influence sedimentation on submerged leaf surfaces of herbaceous vegetation during overflow conditions.

Our aim is to comprehensively examine how leaf traits influence sedimentation in floodplains. We used flumes to experimentally simulate inundation of leaves of 30 species in sediment-rich water and to quantify the effect of traits 
on sediment accumulation on the leaf surface per unit of leaf area. We hypothesize that leaf surface sedimentation increases with decreasing area and length. Sedimentation may also increase with decreasing perimeter and pinnation, caused by reduced turbulence around the leaf. Furthermore, we expect sedimentation to be positively correlated to leaf pubescence and roughness, since both build buffer zones for sediment to settle. We further expect that sedimentation increases with increasing wettability due to increasing contact area and also increases with increasing flexibility due to reduced near-surface turbulence.

\section{Materials and methods}

\section{Selection of the species}

We selected herbaceous plant species to span the gradient of variation in the investigated leaf traits while ensuring that typical floodplain species were also well represented. This was done by categorizing plant leaves a priori using three factors with two to three levels (leaf flexibility: stiff vs flexible, roughness: rough vs smooth, pubescence: dense hairs vs sparse hairs vs no hairs, see Supp 1), and assigning candidate species to these. While the categorization was arbitrary, all categories had clear links to our traits of interest. We used plant community inventories of floodplain meadows along the Mulde River $\left(51^{\circ} 43^{\prime}-46^{\prime} \mathrm{N}, 12^{\circ} 17^{\prime}-18^{\prime} \mathrm{E}\right)$ conducted in the context of the conservation project "Wilde Mulde" (Wilde Mulde-Revitalization of a wild river landscape in Central Germany) and selected 16 herbaceous species observed during these inventories (Supp 1). Then, we supplemented these with 14 additional species from the Botanical Garden of Leipzig to fill gaps in predictor trait space. For each combination of trait categories, we measured a minimum of two different species out of at least two different families. We did not find any species to fill the trait category combinations "stiff" and "dense hairs" with either "rough" or "smooth" species. All species were collected in the Botanical Garden of Leipzig and surroundings, which ensured that we could use fresh plant material for the experiment.

\section{Experimental set-up}

We performed the flume experiment in the greenhouse of the Botanical Garden in Leipzig. The eight flumes were self-made with modified standard aquariums $(30 \times 30 \times 50$ $\mathrm{cm}^{3}$, Fig. 1). We used handcraft clay as sediment $(\varnothing<2 \mu \mathrm{m}$, "Soft-Ton", Glorex), since fine particles are most relevant regarding nutrient bounding (Naiman and Décamps 1997), and larger particles could not stay in a constant solution for longer. A rainwater pump (with power of $400 \mathrm{~W}$,

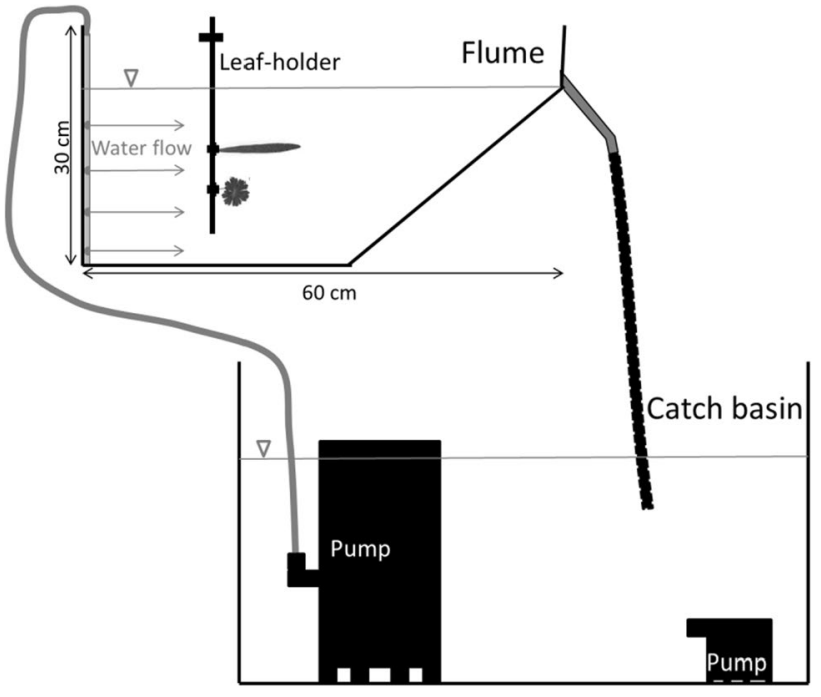

Fig. 1 Sketch of the experimental setup. Experimental flume with the water flowing from left to right, overflows into the catch basin and is pumped up into the inflow of the flume. We fixed the leaves with clips to the leaf-holder within the flume

Tauchpumpe 400, CMI) generated the water flow. Additionally, we placed a second small aquarium pump in the catch basin to avoid sedimentation on its bottom (compactON 1000, EHEIM). Four tubes with four small effluences each distributed the flow in the aquarium unidirectional and as even as possible to simulate natural overbank conditions on a meadow. Nevertheless, there were some reflux and some smaller turbulence in the flume caused by the skewed glass plate at the outlet. The mean flow rate was $13.8 \mathrm{~L} \mathrm{~min}^{-1}$ with mean velocity at the leaf-holder of $5.6 \mathrm{~cm} \mathrm{~s}^{-1}$. The leaf-holder fixed the leaves on a frame with small clips in the middle of the flume. It consisted of three rods beside each other, each with two clips, resulting in six potential positions to fix single leaves (Fig. 1). We cleaned the whole flume set-up every week to avoid algae growth and to keep the amounts of water and sediment in the flume constant. Each week, we solved $38 \mathrm{~g}$ dry clay in $60 \mathrm{~L}$ water per flume to create a saturated solution.

\section{Sample processing}

Of each sampled species, we picked eight leaves and kept them in a moist plastic bag to avoid desiccation during transport. Before fixing the leaves into the flume, we scanned each leaf (Expression 11000XL, Epson) to record the leaf form (Supp 2). To avoid interference between the leaves, we restricted the number of leaves per flume between one and a maximum of six, depending on the size of the leaves. Each run lasted $24 \mathrm{~h}$, and we ran eight flumes simultaneously. Each flume contained one leaf per species. After $24 \mathrm{~h}$, we took leaves carefully out of the flume, washed off 
accumulated sediment from both sides into a small beaker with $40 \mathrm{~mL}$ water, and carefully cleaned them with a soft toothbrush. We filled additional beakers with $40 \mathrm{~mL}$ water of each flume to control for variation in sediment solution per flume and day in subsequent analyses. To quantify the sediment mass, we dried the beakers with solution in a dry oven at $70{ }^{\circ} \mathrm{C}$, removed the sediment, dried the sediment sample again until constant final weight and weighed it afterwards.

We performed a second set of runs to control for the effects of leaf shape and size. For this second experiment, we cut the leaves to a standardized size of $2 \times 6 \mathrm{~cm}^{2}$ with a scalpel. We chose this shape and area to get a standardized leaf area and to include as many species as possible. We included 12 species out of the species set (Supp 1). All other procedures and measurements were done in the same way as with the entire leaves.

\section{Trait measurements}

We sampled ten additional leaves per species used in the flume experiment to measure the following leaf traits: pubescence, roughness, flexibility (few species just have five replicates) and wettability (detailed measurements are listed in Supp 3). All leaves of the sampled species were collected freshly in the vicinity. We used the whole leaf in the flume for all species except for Onobrychis viciifolia where we treated single leaflets as leaves. For measuring the pubescence, we took microscopic photos with an AxioVision SE64 Rel. 4.9 (Zeiss). On an image of approximately $1 \mathrm{~cm}^{2}$, we counted the hairs manually using the software ImageJ (Rasband 1997-2018). The number of hairs was set in relation to the area of the image (hairs $\mathrm{mm}^{-2}$; Supp 4a). On the same images, we measured the venation length per leaf area, as an index of the leaf roughness. This index gives information about the unevenness on the leaf surface. Additionally, we took a microscopic photo of a cross-section of each leaf, which included the mid-vein (Supp 4b). We measured the surface length of the cross-section and the leaf width on the image, and used their ratio as a measure of the roughness. Again, we conducted the image analyses with the software ImageJ (Rasband 1997-2018). As an indicator for the flexibility of the leaves, we measured the resistance to punch with a punch force tester (Electric Test Stand TVM-N with dynamometer FH50, Supp 4c). Each leaf was punched three times at different spots between the leaf veins, and we measured the force needed to penetrate the leaf. For measuring the wettability of a leaf at ambient air pressure, we dropped a single tap water droplet of $0.1 \mathrm{~mL}$ on each leaf surface (Bartell and Merrill 1932; Räsänen et al. 2013; Yuan and Lee 2013; Supp 4d). Then, we took a lateral photo of the droplet with a normal camera (Nikon D5100, Objective Sigma 18-250 mm F3,5-6,3 DC Macro OS HSM, with super macro conversion lens (DCR-250, Raynox)). On the image, we measured the contact angle of the droplet again with the software ImageJ (Rasband 1997-2018).

\section{Statistics}

All statistical analyses were done with the statistical software R (R Core Team 2017). In our main analysis, we ran a linear mixed effect model to investigate how sediment load on entire leaves depended on the various leaf traits we studied. In this model, sediment load was the response variable, the different leaf traits were treated as fixed factors (see Supp 3) and we included species identity, aquarium, leaf ID and position within the aquarium as random factors. For the final model, we removed leaf position as a random factor, since models including it were not parsimonious (tested using AIC). To fulfil model assumptions regarding the normality of the error distribution, the response variable (amount of sediment per leaf area) was natural log transformed. When traits were highly correlated with each other, we removed those least strongly related to sediment load from initial models to avoid multicollinearity. The traits we removed were hair type and density on the abaxial leaf side and the roughness approximated by vein length. Thus, our initial model contained the following traits: $\log ($ area), length, perimeter, pinnation, adaxial hair density, adaxial hair type (category "no hairs" as control hair type), waviness of leaf cross-section, resistance to punch, contact angle and the interaction between $\log ($ area $)$ and the adaxial hair density. We constructed our initial model using the 'Imer' function in the lme4 library (Bates et al. 2015), and applied a REML fitting procedure. We followed a stepwise procedure to remove fixed factors from the initial model that were not significant $(p>0.05)$, until we could select a final model in which all fixed factors were significantly related to sediment load. For standardizing the regression coefficients we used the 'beta' function in the reghelper library (Hughes 2018) and for the coefficients of variation including and excluding the random factors, we used the 'r.squaredGLMM' function in the MuMIn library (Barton 2018).

The same procedure was used for the leaves of standardized size. The random factors were the same (species, aquarium, leaf ID and position), while leaf position was, for the same reason as above, removed from further models. Also for this data set, the traits hair type and density on the abaxial leaf side and the roughness measured by vein length were removed due to multicollinearity with other traits. The initial model for the size-standardized leaves then contained the following traits: adaxial hair density, adaxial hair type, waviness of leaf cross-section, resistance to punch and the contact angle.

For the 12 species, we used both in the main experiment with entire leaves and in the experiment with 
size-standardized leaves, we tested the differences in sedimentation on the leaf surface of each species using paired two-sample $t$ tests.

\section{Results}

\section{Area and pubescence explain sedimentation on entire leaves}

Our analysis of entire leaves showed that traits related to total area and pubescence on the upper side were the strongest predictors of sedimentation on the whole leaf surface. In particular, $\log$ (area), adaxial hair density, adaxial hair type and the interaction between adaxial hair density and $\log$ (area) significantly explained sedimentation (Table 1), and explained a high proportion of its variance $\left(R_{\mathrm{m}}^{2}=0.65\right.$ [variation explained by fixed factors only], $R_{\mathrm{c}}^{2}=0.82$ [variation explained by fixed and random factors]).

Sedimentation on the leaf surface decreased with total leaf area, but only on leaves with a low hair density $(<1$ hair $\mathrm{mm}^{-2}, p<0.01$, Fig. 2). Furthermore, sedimentation was significantly higher on leaves with a high adaxial hair density ( $\geq 1$ hair $\mathrm{mm}^{-2}$ ) compared with leaves with low adaxial hair density $\left(<1\right.$ hair $\mathrm{mm}^{-2} ; p=0.03$; Supp 5a).

Sedimentation also differed in relation to hair type, where it was lowest on leaves without hairs and highest on leaves with split hairs. Significant differences occurred for "no hairs" compared to "single hairs" and "split hairs",

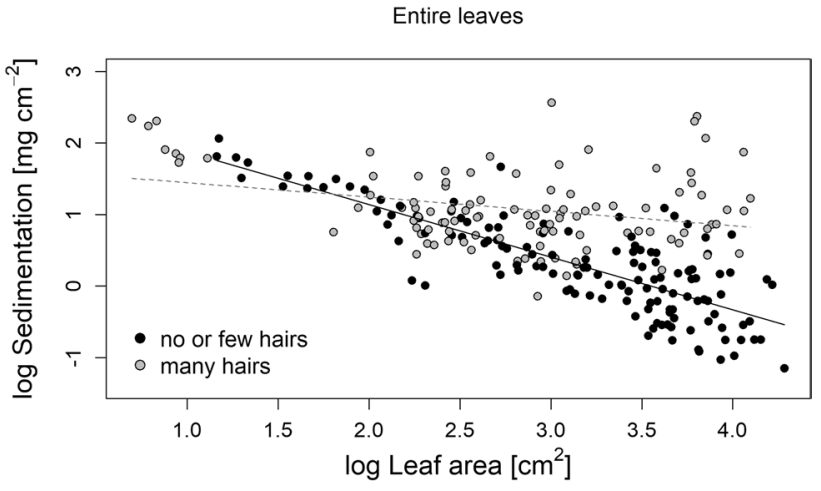

Fig. 2 Relationship of the $\log$ sedimentation $\left(\mathrm{mg} \mathrm{cm}^{-2}\right)$ depending on the log leaf area $\left(\mathrm{cm}^{2}\right)$, for entire leaves. Black dots represent leaves with no or few hairs $\left(<1\right.$ hair $\mathrm{mm}^{-2} ; p<0.01$; black regression line $)$, and grey dots represent leaves with many hairs $\left(\geq 1\right.$ hair $\mathrm{mm}^{-2}$; grey dashed trend line)

and for "split hairs" compared to "felt-like hairs" $(p<0.05$; Fig. 3).

\section{Pubescence and waviness explain sedimentation on size-standardized leaves}

To investigate which leaf traits are driving sedimentation on size-standardized leaves, we also analysed drivers of sedimentation on leaves cut to a standardized size of $2 \times 6$ $\mathrm{cm}^{2}$. Again, adaxial hair density was an important predictor of leaf sedimentation ( $p=0.02$, Supp 5b). Additionally, we found that increasing waviness of a leaf cross-section ( $p=0.04$, Fig. 4), a variable representing the leaf roughness, increased leaf sedimentation. The proportion of variance

Table 1 Statistical model results of the species sets with entire leaves and size-standardized leaves

\begin{tabular}{|c|c|c|c|c|}
\hline & \multicolumn{4}{|c|}{ Entire leaves } \\
\hline & Estimate & Std. error & $t$ value & $p$ value \\
\hline (Intercept) & 0.044 & 0.092 & 0.471 & $<2 \mathrm{e}-16^{* * *}$ \\
\hline Hair type (single hairs) adaxial & 0.231 & 0.109 & 2.129 & $0.044^{*}$ \\
\hline Hair type (split hairs) adaxial & 0.259 & 0.095 & 2.714 & $0.012 *$ \\
\hline Hair type (felt-like hairs) adaxial & 0.033 & 0.102 & 0.323 & 0.750 \\
\hline Hair density (many hairs) adaxial & 0.256 & 0.111 & 2.316 & $0.034^{*}$ \\
\hline Log area & -0.629 & 0.060 & -10.465 & $<2 \mathrm{e}-16^{* * *}$ \\
\hline \multirow{3}{*}{$\begin{array}{l}\text { Interaction hair density (no or few hairs) adaxial } \\
\text { and log area }\end{array}$} & 0.212 & 0.059 & 3.561 & $0.001 * * *$ \\
\hline & \multicolumn{4}{|c|}{ Size-standardized leaves } \\
\hline & Estimate & Std. error & $t$ value & $p$ value \\
\hline (Intercept) & -0.008 & 0.192 & -0.042 & 0.097 \\
\hline Hair density (many hairs) adaxial & 0.460 & 0.171 & 2.694 & $0.025^{*}$ \\
\hline Waviness of a cross-section & 0.398 & 0.171 & 2.334 & $0.045^{*}$ \\
\hline
\end{tabular}

Estimates are standardized and $p$ value was calculated by type II anova with Kenward-Roger method for the $F$ test 


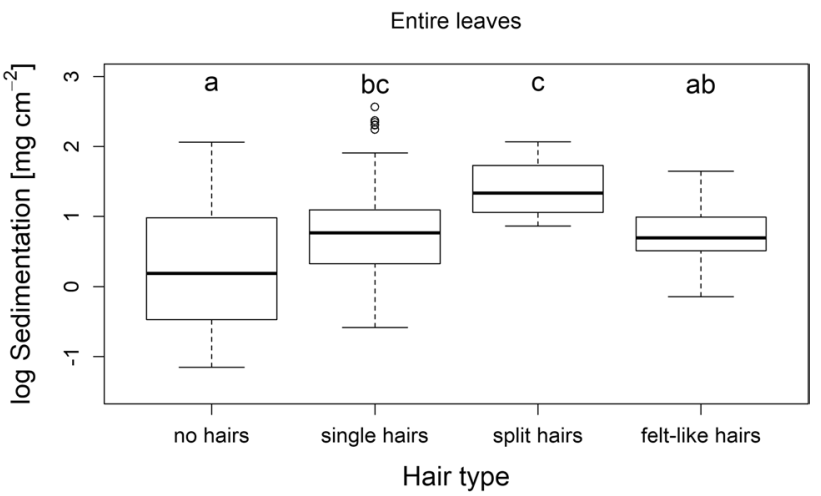

Fig. 3 Boxplot of species set with entire leaves showing the significant differences in accumulated sediment per area depending on the hair types. Significance for differences $(p<0.05)$ indicated by letters $(\mathrm{a}, \mathrm{b}, \mathrm{c})$

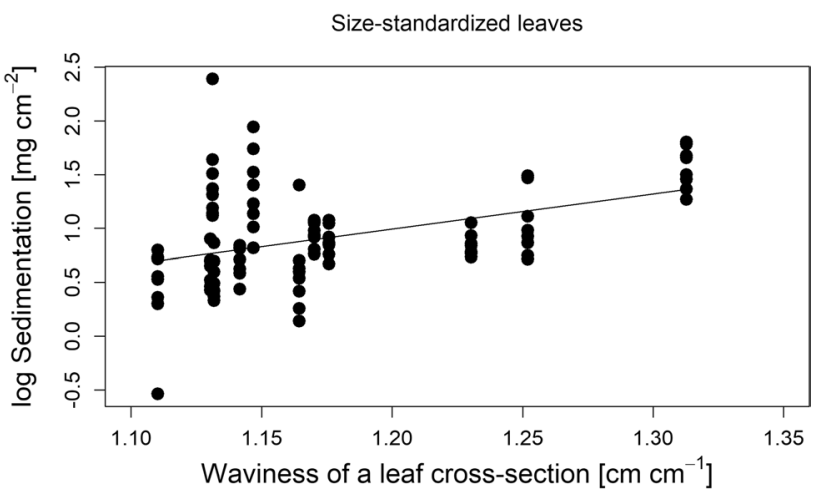

Fig. 4 Relationship between the $\log$ sedimentation $\left(\mathrm{mg} \mathrm{cm}^{-2}\right)$ depending on the waviness of leave cross-sections $\left(\mathrm{cm} \mathrm{cm}^{-1}\right)$ for the species set with size-standardized leaves explained by the fixed factors was $R_{\mathrm{m}}^{2}=0.36$, while random factors also explained a large proportion of variation $R_{\mathrm{c}}^{2}=0.71$ (Table 1).

\section{Within species comparison between entire and size-standardized leaves}

By comparing sedimentation on entire leaves (varying size, $\left.9.44-72.50 \mathrm{~cm}^{2}\right)$ with size-standardized leaves $\left(12 \mathrm{~cm}^{2}\right)$ from the same species, we could experimentally assess how a standardization of size and form of leaves drives sedimentation per leaf area. This comparison showed that for species with low hair density $\left(<1\right.$ hair $\left.\mathrm{mm}^{-2}\right)$ the leaf sedimentation per area was higher on size-standardized (i.e. size-reduced in all cases) leaves for six out of seven species (Fig. 5a). In contrast, sedimentation per area is not affected by sizestandardization (i.e. size-reduction) for four out of the five hairy species ( $\geq 1$ hair $\mathrm{mm}^{-2}$; Fig. $5 b$ ). The only hairy species with significantly more sediment on entire leaves (Solidago canadensis, Fig. 5b), was the species were half of the selected entire leaves were smaller than $12 \mathrm{~cm}^{2}(9.44-11.63$ $\mathrm{cm}^{2}$ ).

These experimental results clearly show the same interaction effect we already observed between the log area and the hair density for the entire leaves (Fig. 2). Sedimentation decreased with increasing area for species with no or few hairs, while there was no significant effect for hairy species.

\section{Discussion}

We showed that leaf traits control the amount of accumulated sediment on leaf surfaces. In our experiment the leaf traits area, pubescence and roughness influence sedimentation significantly, while flexibility and wettability do not. Our
Fig. 5 Boxplots of within species comparison between entire leaves and size-standardized leaves, separated due to the hair density a no or few hairs, b many hairs. Color coded due to the species set
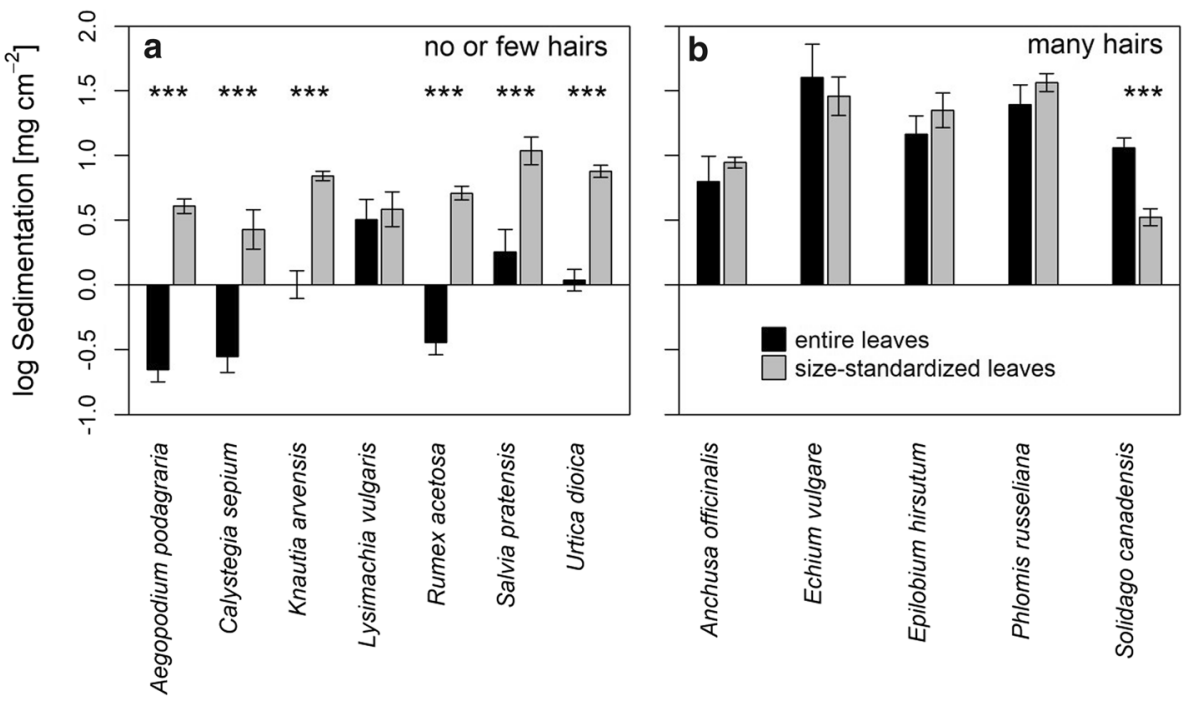
results support our hypothesis that sedimentation increases with decreasing leaf area, although only on leaves with low hair density. Length, perimeter and pinnation of the leaves did not influence sedimentation significantly. Furthermore, we could also confirm the hypothesis of increasing sedimentation with increasing adaxial pubescence and roughness, though the latter matters only on size-standardized leaves.

\section{Area and hair density and their interaction}

Our results show that leaf area and pubescence are the strongest drivers of sediment accumulation on leaf surfaces. Previous studies focusing on how airborne particle deposition is related to leaf area have provided mixed results. While Räsänen et al. (2013) found a decrease of particle deposition with increasing leaf area, Sæbø et al. (2012) and Weber et al. (2014) did not find any significant relationship. Our work provided experimental evidence for a negative relationship between sedimentation and leaf area, but only for leaves with low hair density (Figs. 2, 5). The negative area effect for species with low hair density might be driven by the hydrodynamics along the boundary layer of the leaf surface. Within a laminar flow, a boundary layer forms on the leaf surface and becomes thicker with the flow direction (Nepf 2012). At a certain distance along the surface, the boundary layer starts to become turbulent (Nepf 2012). From that distance onwards, turbulence may hinder sediment to settle during moments of high flow velocity, and the turbulence may cause sediment remobilisation from the leaf surface (Nepf 2012). Although in our experiment, we did not have laminar conditions, the sedimentation seems to follow a similar pattern. Small leaves without hairs may be able to accumulate sediment on the surface within a laminar boundary layer, while larger leaves experience turbulence at the distant part of the leaf resulting in less overall sedimentation. To quantify this effect sedimentation needs to be measured on different parts of the leaf surface. On a floodplain meadow, flow velocity varies and turbulence occur within the vegetation patches, caused by structural parameter of the vegetation, such as stem and patch density (Corenblit et al. 2009,2011; Kervroëdan et al. 2018). This may influence sedimentation on leaf surfaces, additionally. Nevertheless, our experiment enables a first understanding of the process of sedimentation on leaf surfaces explained by leaf traits under constant conditions.

Hairs on a leaf surface present obstacles to the water flow. As a consequence, the main drag force of the water is above the hairs (Nepf 2012). With reduced drag force, the flow velocity and turbulence strength between the hairs are reduced (Nepf 2012), which gives the sediment space and time to settle. However, when hair density is low, the few hairs present are not sufficient to significantly alter water flow, leading to similar flow conditions as on plain surfaces
(Nepf 2012). This explains the high sedimentation on leaves with many hairs compared to the low sedimentation on leaves with few or no hairs (Supp 5a). In addition, hairs enlarge the surface area of the leaves and thereby the surface for sedimentation. In line with this, previous airborne studies showed that densely haired leaves accumulate more particles (Wedding et al. 1975; Sæbø et al. 2012; Räsänen et al. 2013; Weber et al. 2014). Furthermore, for sedimentation on leaf surfaces with many hairs the effects of the boundary layer are negligible, since the hair layer itself acts as a buffer zone, irrespective of whether the flow above is laminar or turbulent (Paul et al. 2014). Within the hair layer, the flow velocity is reduced and sedimentation takes place (Nepf 2012; Paul et al. 2014).

In our study, we used floodplain species and additional non-floodplain species to span the trait gradients. All species we classified as densely haired prior to the experiment were species that typically grow outside of floodplain areas, but the pubescence of our measured data were classified in two groups $\left(<1\right.$ hair $\mathrm{mm}^{-2}$ or $\geq 1$ hair $\left.\mathrm{mm}^{-2}\right)$. Out of the 13 hairy species, 5 species were floodplain species (Artemisia vulgaris, Epilobium hirsutum, Lythrum salicaria, Solidago canadensis, and Stachys palustris). Regarding leaf area, seven species have a below-average leaf area with $<1$ hair $\mathrm{mm}^{-2}$, of which six are floodplain species (Calamagrostis epigejos, Convolvulus arvensis, Deschampsia cespitosa, Plantago lanceolate, Saponaria officinalis, Tanacetum vulgare). This indicates that species with leaf surface traits that are most suitable for leaf sedimentation are well represented among floodplain species. Therefore, management favouring plant species that maximize leaf sedimentation does not require the introduction of exotic species.

\section{Hair type and waviness of cross-section}

Our results also provide evidence that in addition to hair density, the hair type influences surface sedimentation. Leaves without hairs accumulate significantly less sediment than leaves with single hairs or split hairs (Fig. 3). In our study, the category split hairs was represented by only one species (Phlomis russeliana). The species has stellate hairs with five ends forming minute canopies, which create a buffer zone against the flow. From forest canopy studies, it is known that wind flow speed is strongly reduced below the canopy (Oliver 1971; Jiao-jun et al. 2004). Again, this may give space and time for sediment to settle (Paul et al. 2014). While we expected a similar effect for species with felt-like hairs, our results do not provide evidence for this. Leaves with felt-like hairs accumulate significantly less sediment than leaves with split hairs. Hairs are differently constructed, with the main purpose to reduce water loss, but they also fulfil defence purposes (Johnson 1975). In our study, the species with split hairs and felt-like hairs do strongly differ in 
the stiffness, thickness and flexibility of the hairs. The split hairs of Phlomis russeliana are stiff, thick and upright, while the felt-like hairs of Artemisia vulgaris and Potentilla anserina are smooth, thin and flexible. Thus, split hairs are more resistant against the flow and keep standing upright like a forest in the storm, building a canopy underneath which sediment can settle, while felt-like hairs possibly bend with the flow. Also Weber et al. (2014) observed high airborne particle accumulation on species with dense stellate hairs, while Ren et al. (2007) found that species with star-shaped hairs have the strongest cohesive force on the surface. Feltlike hairs still act as obstacle in the flow, however, the accumulated sediment does not significantly differ from leaves with single hairs, or from leaves with no hairs.

When focusing on cut leaves, which had a standardized size and shape, we found that leaf waviness, as a measure of roughness, also significantly increased sedimentation in addition to hair density. Wavier and thus rougher leaves accumulated more sediment, probably through similar mechanisms as those operating on hairy leaves. Strong waves on the leaf provide slipstream areas for sediment to settle. Other studies also found that with increasing leaf roughness the accumulation of airborne particle increases (Little 1977; Pyatt and Haywood 1989; Weber et al. 2014). While our results regarding the effects of leaf waviness are thus in line with our expectations and other studies, we also found that one species, Echium vulgare, obtained the highest sediment load despite low waviness values. However, this might represent a limitation of our waviness measurement. The waviness of our cross-sections only indicates the lateral roughness at one cut at a single location per leaf, rather than an overall measure for leaf roughness. Echium vulgare has small humps with hairs on the surface, but these were not well represented in our measurements. We would suggest that a 3D scan of the macro-roughness of the leaf surface may better capture the overall leaf roughness, and might be a stronger predictor of leaf surface sedimentation than the waviness of cross-sections that we used in our study.

\section{Importance of leaf sedimentation for floodplains}

The magnitude of variation of the accumulated sediment and the significance and comparatively high proportion of explained variance of the presented results $\left(R_{\mathrm{m}}^{2}=0.65\right)$ indicates the importance of leaf surfaces for sediment accumulation. While this was already shown regarding airborne particle capturing (Sæbø et al. 2012; Räsänen et al. 2013; Weber et al. 2014), to our knowledge, this is the first study on sediment accumulation on the leaf surface of inundated herbaceous species in a setting simulating flood events. Sediment retention is a key ecosystem service provided by floodplain vegetation and our study provides evidence that the traits of the leaves influence the extent to which sedimentation occurs. Elliott (2000) already showed that emergent vegetation within a channel is highly relevant for overall sedimentation within the stream and strongly driven by lateral structural complexity of the stand. Fine sedimentation is in general highest within patches of dense herbaceous vegetation compared to patches of post-pioneer shrubland and forest (Corenblit et al. 2009). In this study, we showed that the functional and structural diversity of the vegetation plays a key role for fine sediment retention on plants. This adds to the growing body of the literature providing evidence for the importance of plant diversity and identity for controlling ecosystem functions (Díaz and Cabido 2001). By combining our understanding of on-plant sedimentation with sedimentation in-between plants in future experiments, we will develop a more holistic picture on the capacity of floodplains to filter sediment from the floodwater. This understanding is crucial for enhancing the ecosystem service of sediment and nutrient retention of floodplains, by guiding restoration projects along rivers (Tockner and Stanford 2002; Palmer et al. 2010). Furthermore, increased insights into on-plant sedimentation may improve the management of already existing floodplain meadows.

Acknowledgements Open Access funding provided by Projekt DEAL. First of all, we thank the Federal Ministry of Education and Research (BMBF) and the Federal Agency for Nature Conservation (BfN) for funding the project (Wilde Mulde-Revitalization of a wild river landscape in Central Germany (funding label: 01LC1322E)). We thank Ronny Kubenz, who contributed data from his Master Thesis. We further thank the Botanical Garden for providing the species and the greenhouse space to run the experiment. We also thank our technicians (Kerstin Flieger) and student lab assistants (Karl Andraczek, Maria Kahler and Georg Rieland) for their support with the trait data measurements.

Author contribution statement LK, CS and CW conceptualized the study, while LK, CS, AW and CW designed the experiment. LK conducted the experiment and LK and FvdP analysed the data and did the statistics. LK interpreted the results and wrote the manuscript with input from all co-authors.

Funding Federal Ministry of Education and Research (BMBF) and Federal Agency for Nature Conservation (BfN) funded the project. Project name: Wilde Mulde-Revitalization of a wild river landscape in Central Germany (funding label: 01LC1322E).

Data availability Data will be deposited in the iDiv Data Repository (https://idata.idiv.de) and will get a DOI

\section{Compliance with ethical standards}

Conflict of interest The authors declare no conflict of interest.

Open Access This article is licensed under a Creative Commons Attribution 4.0 International License, which permits use, sharing, adaptation, distribution and reproduction in any medium or format, as long as you give appropriate credit to the original author(s) and the source, provide a link to the Creative Commons licence, and indicate if changes 
were made. The images or other third party material in this article are included in the article's Creative Commons licence, unless indicated otherwise in a credit line to the material. If material is not included in the article's Creative Commons licence and your intended use is not permitted by statutory regulation or exceeds the permitted use, you will need to obtain permission directly from the copyright holder. To view a copy of this licence, visit http://creativecommons.org/licenses/by/4.0/.

\section{References}

Albayrak I, Nikora V, Miler O, O'Hare M (2012) Flow-plant interactions at a leaf scale: effects of leaf shape, serration, roughness and flexural rigidity. Aquat Sci 74(2):267-286. https://doi. org/10.1007/s00027-011-0220-9

Asselman NEM, Middelkoop H, van Dijk PM (2003) The impact of changes in climate and land use on soil erosion, transport and deposition of suspended sediment in the River Rhine. Hydrol Process 17(16):3225-3244. https://doi.org/10.1002/hyp.1384

Bartell FE, Merrill EE (1932) Determination of adhesion tension of liquids against solids. A microscopic method for the measurement of interfacial contact angles. J Phys Chem 36(4):1178-1190. https ://doi.org/10.1021/j150334a010

Barton K (2018) MuMIn: Multi-Model Inference. R package version 1.42.1. CRAN.R-project.org/package $=$ MuMIn

Bates D, Mächler M, Bolker BM, Walker SC (2015) Fitting linear mixed-effects models using lme4. J Stat Softw. https://doi. org/10.18637/jss.v067.i01

Berendse F, van Ruijven J, Jongejans E, Keesstra S (2015) Loss of plant species diversity reduces soil erosion resistance. Ecosystems 18(5):881-888. https://doi.org/10.1007/s10021-015-9869-6

Bernhardt ES, Palmer MA (2011) River restoration: the fuzzy logic of repairing reaches to reverse catchment scale degradation. Ecol Appl 21(6):1926-1931. https://doi.org/10.1890/10-1574.1

Bhushan B, Jung YC, Koch K (2009) Micro-, nano- and hierarchical structures for superhydrophobicity, self-cleaning and low adhesion. Philosophical Transactions of the royal society. Math Phys Eng Sci 367(1894):1631-1672. https://doi.org/10.1098/ rsta.2009.0014

Blanco-Canqui H, Gantzer CJ, Anderson SH, Alberts EE, Thompson AL (2004) Grass barrier and vegetative filter strip effectiveness in reducing runoff, sediment, nitrogen, and phosphorus loss. Soil Sci Soc Am J 68(5):1670-1678. https://doi.org/10.2136/sssaj 2004.1670

Bouwman AF, Bierkens MFP, Griffioen J, Hefting MM, Middelburg JJ, Middelkoop H, Slomp CP (2013) Nutrient dynamics, transfer and retention along the aquatic continuum from land to ocean: towards integration of ecological and biogeochemical models. Biogeosciences 10:1-22. https://doi.org/10.5194/bg-10-1-2013

Burkhardt J, Peters K, Crossley A (1995) The presence of structural surface waxes on coniferous needles affects the pattern of dry deposition of fine particles. J Exp Bot 46(7):823-831. https://doi. org/10.1093/jxb/46.7.823

Carpenter SR, Caraco NF, Correll DL, Howarth RW, Sharpley AN, Smith VH (1998) Nonpoint pollution of surface waters with phosphorus and nitrogen. Ecol Appl 8(3):559-568. https://doi. org/10.1890/1051-0761(1998)008[0559:NPOSWW]2.0.CO;2

Chen S-C, Kuo Y-M, Li Y-H (2011) Flow characteristics within different configurations of submerged flexible vegetation. J Hydrol 398(1-2):124-134. https://doi.org/10.1016/j.jhydrol.2010.12.018

Clarke SJ (2002) Vegetation growth in rivers: influences upon sediment and nutrient dynamics. Prog Phys Geogr 26(2):159-172. https:// doi.org/10.1191/0309133302pp324ra
Conte M, Ennaanay D, Mendoza G, Walter MT, Wolny S, Freyberg D, Nelson E, Solorzano L (2011) Retention of nutrients and sediment by vegetation. In: Kareiva P, Tallis H, Ricketts TH, Daily GC, Polasky S (eds) Natural capital: theory and practice of mapping ecosystem services. Oxford University Press, Oxford, pp 89-110 (chapter 6)

Corenblit D, Steiger J, Gurnell AM, Tabacchi E, Roques L (2009) Control of sediment dynamics by vegetation as a key function driving biogeomorphic succession within fluvial corridors. Earth Surf Proc Land 34(13):1790-1810. https://doi.org/10.1002/esp.1876

Corenblit D, Baas ACW, Bornette G, Darrozes J, Delmotte S, Francis RA, Gurnell AM, Julien F, Naiman RJ, Steiger J (2011) Feedbacks between geomorphology and biota controlling Earth surface processes and landforms: a review of foundation concepts and current understandings. Earth Sci Rev 106(3-4):307-331. https ://doi.org/10.1016/j.earscirev.2011.03.002

Díaz S, Cabido M (2001) Vive la différence: plant functional diversity matters to ecosystem processes. Trends Ecol Evol 16(11):646655. https://doi.org/10.1016/S0169-5347(01)02283-2

Elliott AH (2000) Settling of fine sediment in a channel with emergent vegetation. J Hydraul Eng 126(8):570-577. https://doi. org/10.1061/(ASCE)0733-9429(2000)126:8(570)

Emerson BC, Kolm N (2005) Species diversity can drive speciation. Nature 434(April):1015-1017. https://doi.org/10.1038/nature0345 0

Grizzetti B, Bouraoui F, De Marsily G (2008) Assessing nitrogen pressures on European surface water. Glob Biogeochem Cycl. https:// doi.org/10.1029/2007GB003085

Gurnell AM, Bertoldi W, Corenblit D (2012) Changing river channels: the roles of hydrological processes, plants and pioneer fluvial landforms in humid temperate, mixed load, gravel bed rivers. Earth Sci Rev 111(1-2):129-141. https://doi.org/10.1016/j.earsc irev.2011.11.005

Habersack H, Hein T, Stanica A, Liska I, Mair R, Jäger E, Hauer C, Bradley C (2016) Challenges of river basin management: current status of, and prospects for, the River Danube from a river engineering perspective. Sci Total Environ 543:828-845. https://doi. org/10.1016/j.scitotenv.2015.10.123

Hancock PJ (2002) Human impacts on the stream-groundwater exchange zone. Environ Manag 29(6):763-781. https://doi. org/10.1007/s00267-001-0064-5

Hopkins KG, Noe GB, Franco F, Pindilli EJ, Gordon S, Metes MJ, Claggett PR, Gellis AC, Hupp CR, Hogan DM (2018) A method to quantify and value floodplain sediment and nutrient retention ecosystem services. J Environ Manag 220:65-76. https://doi. org/10.1016/j.jenvman.2018.05.013

Horn R, Richards K (2007) Flow-vegetation interactions in restored floodplain environments. In: Wood PJ, Hannah DM, Sadler JP (eds) Hydroecology and ecohydrology: past, present and future, pp 269-294. doi:10.1002/9780470010198.ch15

Hughes J (2018) reghelper: Helper functions for regression analysis. R package version 0.3.4. https://CRAN.R-project.org/packa ge $=$ reghelper

Hunter HM, Walton RS (2008) Land-use effects on fluxes of suspended sediment, nitrogen and phosphorus from a river catchment of the Great Barrier Reef, Australia. J Hydrol 356(1-2):131-146. https ://doi.org/10.1016/j.jhydrol.2008.04.003

James CS, Jordanova AA, Nicolson CR (2002) Flume experiments and modelling of flow-sediment-vegetation interactions. In: Dyer FJ, Thoms MC, Olley JM (eds) The structure, function and management implications of fluvial sedimentary systems. International Association of Hydrological Sciences (IAHS) Press, Centre for Ecology and Hydrology, Wallingford, IAHS Publication, 276, pp 3-9 
Jiao-jun Z, Xiu-fen L, Yutaka G, Takeshi M (2004) Wind profiles in and over trees. J For Res 15(4):305-312. https://doi.org/10.1007/ bf02844959

Johnson HB (1975) Plant pubescence: an ecological perspective. Bot Rev 41(3):233-258. https://doi.org/10.1007/BF02860838

Jones JI, Collins AL, Naden PS, Sear DA (2012) The relationship between fine sediment and macrophytes in rivers. River Res Appl 28(7):1006-1018. https://doi.org/10.1002/rra.1486

Karr JR, Schlosser IJ (1978) Water resources and the land-water interface. Science 201(4352):229-234. https://doi.org/10.1126/scien ce.201.4352.229

Kervroëdan L, Armand R, Saunier M, Ouvry J, Faucon M (2018) Plant functional trait effects on runoff to design herbaceous hedges for soil erosion control. Ecol Eng 118(December 2017):143-151. https://doi.org/10.1016/j.ecoleng.2018.04.024

Koch K, Bhushan B, Barthlott W (2008) Diversity of structure, morphology and wetting of plant surfaces. Soft Mater 4(10):19431963. https://doi.org/10.1039/b804854a

Koch K, Bhushan B, Barthlott W (2009) Multifunctional surface structures of plants: an inspiration for biomimetics. Prog Mater Sci 54(2):137-178. https://doi.org/10.1016/j.pmatsci.2008.07.003

Little P (1977) Deposition of 2.75, 5.0 and $8.5 \mu \mathrm{m}$ particles to plant and soil surfaces. Environ Pollut 12(4):293-305. https://doi. org/10.1016/0013-9327(77)90023-4

Manners R, Schmidt J, Wheaton JM (2013) Multiscalar model for the determination of spatially explicit riparian vegetation roughness. J Geophys Res Earth Surf 118(1):65-83. https://doi. org/10.1029/2011JF002188

Naiman RJ, Décamps H (1997) The ecology of interfaces: Riparian zones. Annu Rev Ecol Syst 28:621-658. https://doi.org/10.1146/ annurev.ecolsys.28.1.621

Neinhuis C, Barthlott W (1998) Seasonal changes of leaf surface contamination in beech, oak, and ginkgo in relation to leaf micromorphology and wettability. New Phytol 138(1):91-98. https://doi.org /10.1046/j.1469-8137.1998.00882.x

Nepf HM (2012) Hydrodynamics of vegetated channels. J Hydraul Res 50(3):262-279. https://doi.org/10.1080/00221686.2012.696559

Oliver HR (1971) Wind profiles in and above a forest canopy. Q J R Meteorol Soc 97(414):548-553. https://doi.org/10.1002/qj.49709 741414

Ortiz AC, Ashton A, Nepf H (2013) Mean and turbulent velocity fields near rigid and flexible plants and the implications for deposition. J Geophys Res Earth Surf 118(4):2585-2599. https://doi. org/10.1002/2013JF002858

Otten A, Herminghaus S (2004) How plants keep dry: a physicist's point of view. Langmuir 20(6):2405-2408. https://doi. org/10.1021/la034961d

Palmer MR, Nepf HM, Pettersson TJR, Ackerman JD (2004) Observations of particle capture on a cylindrical collector: implications for particle accumulation and removal in aquatic systems. Limnol Oceanogr 49(1):76-85. https://doi.org/10.4319/lo.2004.49.1.0076

Palmer MA, Menninger HL, Bernhardt E (2010) River restoration, habitat heterogeneity and biodiversity: a failure of theory or practice? Freshw Biol 55(s1):205-222. https://doi.org/10.111 $1 / \mathrm{j} .1365-2427.2009 .02372 . \mathrm{x}$

Pan C, Ma L, Shangguan Z, Ding A (2011) Determining the sediment trapping capacity of grass filter strips. J Hydrol 405(1-2):209216. https://doi.org/10.1016/j.jhydrol.2011.05.027

Paul M, Thomas RE, Dijkstra JT, Penning WE, Vousdoukas MI (2014) Plants, hydraulics and sediment dynamics. In: Frostick LE, Thomas RE, Johnson MF, Rice SP, McLelland SJ (eds) Users guide to ecohydaulic modelling and experimentation: experience of the ecohydraulic research team (PICES) of the HYDRALAB Network. CRC Press, Balkema, pp 91-203

Pyatt FB, Haywood WJ (1989) Air borne particulate distributions and their accumulation in tree canopies, Nottingham, UK.
Environmentalist 9(4):291-298. https://doi.org/10.1007/BF022 41830

Quilbé R, Rousseau AN, Duchemin M, Poulin A, Gangbazo G, Villeneuve J-P (2006) Selecting a calculation method to estimate sediment and nutrient loads in streams: application to the Beaurivage River (Québec, Canada). J Hydrol 326(1-4):295-310. https://doi. org/10.1016/j.jhydrol.2005.11.008

R Core Team (2017) R: a language and environment for statistical computing. Vienna, Austria: R Foundation for Statistical Computing. Retrieved from https://www.R-project.org/

Räsänen JV, Holopainen T, Joutsensaari J, Ndam C, Pasanen P, Rinnan $\AA$, Kivimäenpää M (2013) Effects of species-specific leaf characteristics and reduced water availability on fine particle capture efficiency of trees. Environ Pollut 183:64-70. https://doi. org/10.1016/j.envpol.2013.05.015

Rasband WS (1997-2018) ImageJ, U. S. National Institutes of Health, Bethesda, Maryland, USA, https://imagej.nih.gov/ij/

Ren L, Wang S, Tian X, Han Z, Yan L, Qiu Z (2007) Non-smooth morphologies of typical plant leaf surfaces and their anti-adhesion effects. J Bionic Eng 4(1):33-40. https://doi.org/10.1016/S1672 $-6529(07) 60010-9$

Rovira A, Alcaraz C, Trobajo R (2016) Effects of plant architecture and water velocity on sediment retention by submerged macrophytes. Freshw Biol 61(5):758-768. https://doi.org/10.1111/fwb.12746

Sæbø A, Popek R, Nawrot B, Hanslin HM, Gawronska H, Gawronski SW (2012) Plant species differences in particulate matter accumulation on leaf surfaces. Sci Total Environ 427-428:347-354. https://doi.org/10.1016/j.scitotenv.2012.03.084

Sand-Jensen K (1998) Influence of submerged macrophytes on sediment composition and near-bed flow in lowland streams. Freshw Biol 39:663-679. https://doi.org/10.1046/j.1365-2427.1998.00316 .X

Sharma P, Rai SC (2004) Streamflow, sediment and carbon transport from a Himalayan watershed. J Hydrol 289(1-4):190-203. https ://doi.org/10.1016/j.jhydrol.2003.11.023

Steiger J, Tabacchi E, Dufour S, Corenblit D, Peiry J-L (2005) Hydrogeomorphic processes affecting riparian habitat within alluvial channel-floodplain river systems: a review for the temperate zone. River Res Appl 21(7):719-737. https://doi.org/10.1002/ $\operatorname{rra} .879$

Taylor KG, Owens PN, Batalla RJ, Garcia C (2008) Sediment and contaminant sources and transfers in river basins. In: Owens PN (ed) Sustainable management of sediment resources: sediment management at the river basin scale. Elsevier, Amsterdam, pp 83-135. https://doi.org/10.1016/S1872-1990(08)80006-24

Thoms MC (2003) Floodplain —river ecosystems: lateral connections and the implications of human interference. Geomorphology 56(3-4):335-349. https://doi.org/10.1016/S0169-555X(03)00160 $-0$

Tockner K, Stanford JA (2002) Riverine flood plains: present state and future trends. Environ Conserv 29(3):308-330. https://doi. org/10.1017/S037689290200022X

Turnpenny AWH, Williams R (1980) Effects of sedimentation on the gravels of an industrial river system. J Fish Biol 17(6):681-693. https://doi.org/10.1111/j.1095-8649.1980.tb02802.x

Walling DE, Owens PN, Carter J, Leeks GJL, Lewis S, Meharg AA, Wright J (2003) Storage of sediment-associated nutrients and contaminants in river channel and floodplain systems. Appl Geochem 18(2):195-220. https://doi.org/10.1016/S0883-2927(02)00121-X

Wang H, Shi H, Li Y, Wang Y (2014) The effects of leaf roughness, surface free energy and work of adhesion on leaf water drop adhesion. PLoS ONE 9:e107062. https://doi.org/10.1371/journ al.pone. 0107062

Weber F, Kowarik I, Säumel I (2014) Herbaceous plants as filters: immobilization of particulates along urban street corridors. 
Environ Pollut 186:234-240. https://doi.org/10.1016/j.envpo 1.2013.12.011

Wedding JB, Carlson RW, Stukel JJ, Bazzaz FA (1975) Aerosol deposition on plant leaves. Environ Sci Technol 9(2):151-153. https:// doi.org/10.1021/es60100a004

Wilde Mulde (Wilde Mulde-Revitalization of a wild river landscape in Central Germany). https://www.nbs-forschung-umsetzung. de/292.php
Yuan Y, Lee RT (2013) Contact angle and wetting properties. In: Bracco G, Holst B (eds) Surface science techniques, Springer Series in Surface Sciences, vol 51, Springer, Berlin, Heidelberg 